\title{
REAVI
}

\section{A PERCEPÇÃO DOS MAGISTRADOS ÀS MUDANÇAS NA LEGISLAÇÃO TRABALHISTA E O PERITO CONŢ́B́BIL}

\author{
THE MAGISTRATES 'PERCEPTION TO CHANGES IN THE \\ LABOR LEGISLATION AND ACCOUNTING EXPERT
}

\author{
Paulo César de Melo Mendes * \\ Carolina Côrtes Ribeiro **
}

\begin{abstract}
RESUMO
O objetivo é estudar a percepção dos magistrados em relação às mudanças na legislação trabalhista e o papel dos peritos contábeis. Para alcançar o objetivo, foi realizada uma pesquisa de campo. A amostra da pesquisa, seria composta por todos os Magistrados da Circunscrição de Brasília, mas nem todos aceitaram. Assim, a amostra final foi composta por dez juízes titulares do Tribunal Regional do Trabalho da $10^{\mathrm{a}}$ Região. O trabalho apresenta as mudanças mais significativas na visão dos magistrados, e o posicionamento deles em relação as mudanças serem positivas ou negativas. Com base na Análise de Conteúdo de Bardin (2011), realizou-se a divisão em categorias temáticas e concluiu-se que há inúmeros pontos controvertidos na nova lei e alguns são considerados pelos magistrados como inconstitucionais. Para os peritos contadores, a Reforma Trabalhista pode trazer dois impactos: o primeiro é uma nova possibilidade de trabalho, pois agora há a necessidade de os pedidos serem liquidados desde o início e assim a parte irá procurar os serviços do contador já na fase inicial do processo; o segundo é que agora a responsabilidade pelo pagamento dos honorários periciais passa a ser da parte sucumbente na pretensão objeto da perícia, ainda que beneficiária da justiça gratuita. Isso poderá gerar uma carência de peritos contábeis.
\end{abstract}

Palavras-chave: Reforma Trabalhista. Magistrados. Perito Contador. Perícia Contábil. Justiça do Trabalho.

\begin{abstract}
The objective is to study the perceptions of magistrates regarding changes in labor legislation and the role of accounting experts. To reach the goal, a field survey was conducted. The sample of the research, would be composed by all the Magistrates of the Circumscription of Brasília, but not all accepted. Thus, the final sample consisted of ten judges holding the 10 th Regional Labor Court. The paper presents the most significant changes in the magistrates' view, and their position in relation to the changes are positive or negative. Based on Bardin's Content Analysis (2011), the division was divided into thematic categories and it was concluded that there are numerous controversial points in the new law and some are considered by the magistrates as unconstitutional. For the accountants, the Labor Reform can bring two impacts: the first is a new possibility of work, because now there is the need for the requests to be settled from the beginning and thus the party will seek the services of the accountant already in the initial phase of the process; the second is that now the responsibility for the payment of expert fees becomes the succumbing party in the claim object of the expert, even if beneficiary of the free trial. This may be due to a lack of accounting experts.
\end{abstract}

\footnotetext{
*UnB - Universidade de Brasília. E-mail: mendes@unb.br

** UnB - Universidade de Brasília. E-mail: ccortesribeiro@gmail.com

Revista Eletrônica do Alto Vale do Itajaí - REAVI, v.09, n 15, p. 013-031, dez. 2020. ISSN: 


\section{REAVI}

Keywords: Labor reform. Magistrates. Accountant. Accounting Skills. Work justice.

\section{INTRODUÇÃO}

A Consolidação das Leis do Trabalho (CLT) era a lei mais antiga que vinha sendo ajustada periodicamente e mesmo assim, não caracterizava a situação geral dos trabalhadores. Contudo, representava uma compilação de leis trabalhistas que reunia as normas disciplinares das relações individuais e coletivas de trabalho, além das concernentes a procedimentos administrativos da Justiça do Trabalho (CEZAR, 2008).

Promulgada em 1940, na era Vargas, não acompanhou a atualização no tempo e as novas modalidades trabalhistas impostas pela modernidade e as necessidades do trabalhador, do empregador e da Justiça do Trabalho tornando-se antiquada e obsoleta. Durante esse tempo a lei sofreu pequenos ajustes, porém nenhum tão significativo quanto a Reforma Trabalhista.

A fim de adequar a legislação às novas relações de trabalho, foi aprovada a Reforma Trabalhista. A Lei ${ }^{\circ} 13.467$ de 13 de julho de 2017 entrou em vigor em 11 de novembro de 2017 e conta com muitas alterações que irão modificar as relações no âmbito trabalhista. Segundo Melek (2017), o ato de ajustar a lei era realmente necessário. Porém o que se questiona é se houve uma modificação de forma correta e justa, se houve um amadurecimento necessário das questões que foram alteradas de modo a não trazer retrocessos de direitos. Há muita crítica sobre vários pontos trazidos e suprimidos pela Reforma, porém, também há pessoas que defendem as alterações como vantajosas.

Cabe ao Juiz decidir os feitos que tramitam na Justiça Trabalhista, resolvendo questões de direito nos litígios laborais. Dispõe o art. $8^{\circ}$ do $\mathrm{CPC} / 15$ :

\footnotetext{
Ao aplicar o ordenamento jurídico, o juiz atenderá aos fins sociais e às exigências do bem comum, resguardando e promovendo a dignidade da pessoa humana $\mathrm{e}$ observando a proporcionalidade, a razoabilidade, a legalidade, a publicidade e a eficiência.
}

Nos processos em que são necessários conhecimentos técnicos que não são do domínio do juízo, a figura do perito surge como auxiliar do magistrado. O perito contábil possui um papel fundamental na Justiça do Trabalho, que na maioria dos casos possui cálculos complexos, onde se faz necessário um especialista na área para executar o cálculo. O cálculo apresentado pelo perito contábil ao juízo é um elemento de prova, sendo assim, leva à instancia decisória elementos necessários para a justa solução do litígio (BRASIL, NBC TP 01, 2015).

O trabalho do perito se consubstancia no laudo pericial, nele os fatos relativos à lide, quando de natureza técnica ou científica, são transformados em verdade formal por meio do emprego de metodologia própria. O perito realiza um conjunto de procedimentos técnicos através de exame, vistoria, investigação, arbitramento, avaliação ou certificação.

Evidencia-se na NBC T 13.4.2 - DA PERÍCIA CONTÁBIL: "A preparação e a redação do laudo são de exclusiva responsabilidade de perito contábil.” A realização de perícia contábil exige algumas qualificações do profissional, que são: possuir registro no Conselho Regional de Contabilidade (CRC) e aprovação no Exame de Qualidade Técnica - Peritos Contábeis (EQT-PC). O passo seguinte é o registro no Cadastro Nacional de Peritos Contábeis (CNPC). O CNPC tem como objetivo auxiliar a Justiça e a sociedade, oferecendo uma lista de peritos contábeis identificados por área de atuação e localização geográfica.

Revista Eletrônica do Alto Vale do Itajaí - REAVI, v.09, n 15, p. 013-031, dez. 2020. ISSN: 2316-4190, DOI 10.5965/2316419009152020013 


\section{REAVI}

Com a nova CLT, profissionais que atuam na área da justiça trabalhista, patrões e os trabalhadores deverão estar ajustados a essa nova realidade para observar os reais impactos da reforma, como, por exemplo, se houve redução dos conflitos e das demandas trabalhistas.

Tendo em vista a relevância dos impactos que as mudanças na legislação trabalhista irão trazer, e do papel fundamental que o perito contábil exerce no âmbito da Justiça do Trabalho, é de extrema importância, uma pesquisa para se ter a opinião dos magistrados sobre as alterações feitas. É necessário investigar até que ponto as mudanças trouxeram benefícios para a sociedade e se há pontos negativos e controversos.

Com essa percepção, espera-se esclarecer os principais pontos da Reforma Trabalhista e qual o posicionamento dos juízes frente às novas ações nos tribunais do trabalho. O contador, como peça fundamental para a produção de provas periciais, necessita estar afinado em relação à nova CLT.

Considerando-se os pontos apresentados, o presente estudo estabelece como problema de pesquisa: Qual a percepção dos magistrados em relação às mudanças na legislação trabalhista e o papel dos peritos contábeis nessa jornada?

Assim, o objetivo geral passa a ser captar a opinião dos juízes em relação às mudanças trazidas com a Reforma Trabalhista, quais os pontos que, na opinião do magistrado, ficaram controvertidos e se existe expectativa de redução nos processos trabalhistas. Outro objetivo específico para atingir o objeto maior dessa pesquisa é esclarecer qual o papel do perito judicial e do perito assistente na visão do juízo para a resolução dos conflitos que podem vir a surgir com a nova lei do trabalho.

Com a opinião do magistrado espera-se melhorar o processo acadêmico focado na formação do aluno de graduação em ciências contábeis. E, de forma específica, para os graduandos que almejam atuar como peritos e auxiliares dos magistrados para a resolução de litígios nas varas trabalhistas.

Para o efetivo desenvolvimento dos objetivos específicos em um corpo consistente de análise e argumentação, adota-se como processo metodológico uma abordagem objetiva e qualitativa, com base em um estudo comparativo do conteúdo das obras de diferentes autores, em uma revisão bibliográfica e documental que permita um maior aprofundamento sobre o tema da pesquisa. Para coleta de dados foi realizada entrevista com dez juízes do Tribunal Regional do Trabalho da $10^{\mathrm{a}}$ Região-circunscrição de Brasília. Para a análise das entrevistas, empregou-se a Análise de Conteúdo de Bardin (2011).

Esse trabalho encontra-se organizado em 5 capítulos, sendo esta introdução o primeiro deles. No Capítulo 2, será apresentada a revisão teórica. No Capítulo 3, aprofunda-se a metodologia utilizada para a realização da pesquisa. A coleta de dados e análise será abordada no Capítulo 4. O conteúdo do Capítulo 5 traz considerações finais.

\section{REFERENCIAL TEÓRICO}

Destaca-se a respeito da percepção dos magistrados em relação às mudanças na legislação trabalhista e qual será o papel dos peritos contábeis nessa nova fase da Justiça do Trabalho.

Revista Eletrônica do Alto Vale do Itajaí - REAVI, v.09, n 15, p. 013-031, dez. 2020. ISSN: 2316-4190, DOI 10.5965/2316419009152020013 
O magistrado exerce a importantíssima função de solução de litígios, controle da constitucionalidade das leis, tutela dos direitos fundamentais e garantia da preservação e desenvolvimento do Estado Constitucional e Democrático de Direito contemplado na Constituição de 1988 (PISKE, 2010).

Segundo Piske (2010), o magistrado deve investigar a constitucionalidade da lei. As leis envolvem valores, portanto sua aplicação não deve ser feita de forma automática, sendo necessária sua interpretação. Piske (2010, s/p) afirma que "O juiz deve estar atento às transformações do mundo moderno, porque, ao aplicar o Direito, não pode desconhecer os aspectos sociais, políticos e econômicos dos fatos que lhe são submetidos.".

Dispõe o art. $8^{\circ}$ do Código de Processo Civil (BRASIL, CPC, 2015) que o juiz deverá atender aos fins sociais e às exigências do bem comum, resguardar e promover a dignidade da pessoa humana e observar a proporcionalidade, a razoabilidade, a legalidade, a publicidade e a eficiência.

Diante da afirmação da autora e do que é disposto no CPC, é possível visualizar a importância de se ter conhecimento da opinião dos magistrados em relação à Reforma Trabalhista. É necessária uma pesquisa para esclarecer quais as mudanças mais significativas na CLT na visão dos juízes e se ficaram pontos controvertidos na nova lei. Pois, como cabe ao magistrado o controle da constitucionalidade das leis e a tutela dos direitos fundamentais, sua opinião em relação à Reforma Trabalhista é de interesse de toda sociedade.

\subsection{PERITO CONTADOR}

A perícia na área da contabilidade é um dos tipos de perícias existentes na Justiça do Trabalho, por isso pode ser afetada pelas mudanças que ocorrem no âmbito da justiça trabalhista, como a recente mudança ocorrida da CLT. A respeito da origem da palavra perito, Caldeira (2000) afirma:

A origem do termo perito vem do latim peritus e significa aquele que entende, conhece profundamente, que sabe por experiência; em inglês derivou para expert e em francês para expertise. É aquele que, especialmente, pode conhecer e entender determinados fatos, ou pela sua técnica ou ciência, normalmente, interpreta o significado de tais fatos.

Caldeira (2000), complementa que o exercício da profissão de perito, sendo de um auxiliar da justiça, requer um bom equilíbrio emocional, moral, legal, capacidade técnica e uma responsabilidade enorme para que suas afirmações, que envolvem interesses e valores, sejam consideradas pelas partes e autoridades como um meio de prova.

Júnior et al. (2013), o juiz utiliza a prova pericial para buscar a verdade dos fatos. Mediante a convicção fundamentada na perícia, o juiz é capaz de realizar justo pronunciamento e atribuir a cada qual o que por direito lhe pertence. Dessa forma, a perícia constitui elemento fundamental para a convicção racional do magistrado sobre os fatos a serem por ele julgados.

Consta no Art. 156, do CPC, que quando a prova do fato depender de conhecimento técnico ou científico que não for de domínio do magistrado, o juiz será assistido por um perito. Nesse contexto, entra a figura do perito contador, para auxiliar o magistrado quando for necessário conhecimento científico e técnico na área contábil. Salvo quando as partes, na inicial e na contestação, apresentarem, sobre as questões de fato, pareceres técnicos ou documentos

Revista Eletrônica do Alto Vale do Itajaí - REAVI, v.09, n 15, p. 013-031, dez. 2020. ISSN: 2316-4190, DOI 10.5965/2316419009152020013 


\title{
REAVI
}

elucidativos que considerar suficientes. Neste caso, o juiz poderá dispensar prova pericial, de acordo com o artigo 472 do CPC (BRASIL, 2015).

Segundo a norma que estabelece os critérios inerentes à atuação do contador na condição de perito, a Norma Brasileira de Contabilidade - NBC PP 01, de 27 de fevereiro de 2015: "Perito é o contador, regularmente registrado em Conselho Regional de Contabilidade, que exerce a atividade pericial de forma pessoal, devendo ser profundo conhecedor, por suas qualidades e experiências, da matéria periciada.".

A norma faz a diferenciação entre perito do juízo e perito-assistente. Perito do juízo é aquele nomeado pelo juiz, árbitro, autoridade pública ou privada para exercício da perícia contábil. Já o perito-assistente é o contratado e indicado pela parte em perícias contábeis.

Em relação ao perito-assistente a norma ainda conceitua que:

\begin{abstract}
A indicação ou a contratação de perito-assistente ocorre quando a parte ou a contratante desejar ser assistida por contador, ou comprovar algo que dependa de conhecimento técnico-científico, razão pela qual o profissional só deve aceitar o encargo se reconhecer estar capacitado com conhecimento suficiente, discernimento, com irrestrita independência e liberdade científica para a realização do trabalho.
\end{abstract}

A importância de o trabalho pericial contábil ser acompanhado pelos peritos-assistentes é posta em evidencia por Figueiredo (2003). O autor diz que, devido ao fato dos peritosassistentes terem o interesse de defender os seus clientes, eles farão de tudo para que nada seja omitido no laudo. A consequência disso é um trabalho pericial que tende a ter boa qualidade, sendo apresentado de forma técnica, cientifica e fundamentada.

Devida a responsabilidade do perito em poder produzir solução para a lide, o perito contador possui responsabilidade Civil e Penal. A legislação civil determina responsabilidades e penalidades para o profissional que exerce a função de perito-contador, as quais consistem em multa, indenização e inabilitação. A legislação penal estabelece penas de multa, detenção e reclusão para os profissionais que exercem a atividade pericial que vierem a descumprir as normas legais.

O profissional poderá ser impedido ou suspenso de exercer a perícia quando houver situações fáticas ou circunstanciais que o impossibilite de realizar atividade pericial em processo judicial ou extrajudicial, inclusive arbitral.

O perito deve ter zelo profissional, ou seja, ter cuidado na execução de suas tarefas, em relação à sua conduta, documentos, prazos, tratamento dispensado às autoridades, aos integrantes da lide e aos demais profissionais, de forma que sua pessoa seja respeitada, seu trabalho levado a bom termo e, consequentemente, o laudo pericial contábil e o parecer pericial contábil dignos de fé pública (BRASIL, NBC PP 01, 2015).

Em razão das competências atribuídas ao perito contador, vê-se a relevância de pesquisa no âmbito da Justiça Trabalhista para esclarecer se esses profissionais da contabilidade serão afetados de alguma forma em virtude das mudanças na CLT pela Lei $\mathrm{n}^{\circ} 13.467$ de 13 de julho de 2017.

\subsection{OUTRAS PESQUISAS SOBRE O ASSUNTO}

O assunto sobre Reforma Trabalhista é controverso e polêmico à medida que retrata uma questão imperial de trato e reconhecimento pelo trabalho, sem deixar as características politicas existentes. Há mais de 20 anos que a Lei trabalhista não recebia uma forte atualização das práticas existentes, dificultando a interpretação e contribuindo com o risco trabalhista.

Revista Eletrônica do Alto Vale do Itajaí - REAVI, v.09, n 15, p. 013-031, dez. 2020. ISSN: 2316-4190, DOI 10.5965/2316419009152020013 
Mudanças significativas foram reconhecidas. Contudo seus impactos ainda surtirão efeitos ao logo da sua aplicação.

Dentro da polêmica existente há o item sobre os honorários de sucumbência e as custas processuais realizadas pelo sucumbente à causa, que muitas vezes se declara sem condições de pagamento de custas com aceite do Magistrado e ao final, caso haja decisão contrária, tem que realizar as custas finais. Parece inconstitucional e sem coerência.

Em uma pesquisa recente sobre percepção dos peritos contábeis sobre a influência da Reforma Trabalhista em relação aos honorários periciais no âmbito da Justiça do Trabalho no Estado do Paraná, Mathias e Junior (2020) apontam que há vantagens de atuar como perito contábil trabalhista, pois não houve impacto significativo no exercício da função visto que ainda existem demandas de execuções que continuam sendo regulamentadas pela antiga legislação e na maioria dos processos os honorários recebidos continuam como era antes da reforma, mas os profissionais perceberam que houve declínio de novas reclamações trabalhistas.

Santos (2017) destaca que a Reforma Trabalhista possibilitou o cumprimento das promessas iniciais, influenciando de modo significativo nos direitos do trabalhador hipossuficiente enquanto não conseguiu fomentar a atividade empresarial.

Quanto aos custos e a insegurança jurídica, Dias e Cavalcante (2019), retratam que não houve reduções de custos e de insegurança jurídica nos contratos analisados e que os reflexos das inovações legislativas devem ser verificados após a consolidação dos entendimentos jurisprudenciais sobre a terceirização. Os autores concluíram que as inovações legislativas ocorridas em 2017 tendem a favorecer a terceirização nas empresas no Brasil, porém de forma diferida.

Por outro lado, as alterações impostas a partir da reforma da legislação trabalhista ainda geram projeções diversas quanto ao cenário das demandas trabalhistas no Brasil. De acordo com Carvalho (2017) existem pontos onde a Reforma Trabalhista, levando em conta seu intuito de reduzir as despesas do governo e também acelerar a economia, deixa a desejar e pode sofrer um revés. Ainda segundo Carvalho (2017) dispensar a necessidade de homologação no sindicato ou MPT pode levar a conflitos, exacerbados pela substituição do IPCA-E (Índice Nacional de Preços ao Consumidor Amplo Especial) pela TR (Taxa Referencial) como índice de correção monetária.

Contrariando a suposição do aumento das demandas no âmbito da justiça do trabalho, Andrade (2017) projeta que deverá haver uma contração de demandas, dado o caráter conciliatório das novas regras que regem os pactos trabalhistas. Para Andrade (2017) flexibilização de direitos não significa suprimi-los, sendo a Reforma Trabalhista capaz de dar mais poder a acordos coletivos de modo que seus termos prevaleçam em caso de demanda judicial.

Figueiras et al (2019) destacam outras consequências sobre as mudanças: no campo jurídico, há tendência de leilão ou oferta da força de trabalho, reduzindo a proteção aos trabalhadores; 2) no campo econômico, as promessas das reformas podem não se confirmar e seus impactos são controversos e a generalização da mão de obras se tornar limitada; 3) os impactos sociais são parecidos e generalizáveis, e implicam piora na venda e uso da força de trabalho na medida da efetividade das reformas. Os mercados de trabalho vivem, em geral, uma trajetória que se inicia desde a década de 1990, que deteriora, mas (ainda) sem desestruturar, o conjunto do padrão de gestão do trabalho.

Segundo Figueiras et al (2019) A redução de custos do trabalho após as reformas parece incontroversa nos casos analisados. Já uma relação positiva entre reforma e nível de emprego é, nas hipóteses mais otimistas, duvidosa. Ademais, em países que alternaram reformas 


\section{REAVI}

"flexibilizantes" e medidas de proteção ao trabalho, o desempenho do mercado de trabalho nos períodos subsequentes à implementação das reformas é muito inferior ao registrado após as medidas protetivas.

Mas nenhuma pesquisa buscou a opinião dos juízes diretamente ao cômputo da Lei. Sua aplicação e suas consequências e nem quanto a posição direta sobre a opinião dos peritos judiciais trabalhistas.

Dessa forma, é importante buscar a opinião dos magistrados que aplicam a Lei e suas possíveis consequências. Assim, busca-se a opinião sobre esses magistrados sobre assuntos como apontados no quadro abaixo:

Quadro 1 - Quadro Comparativo das mudanças pela Lei 13.467/2017

\begin{tabular}{|c|c|}
\hline Como era antes da reforma & Depois da Lei 13.467 \\
\hline $\begin{array}{l}\text { Disposição ao Empregador: Considerava o } \\
\text { efetivo período em que o empregado estivesse a } \\
\text { disposição do empregador aguardando ou } \\
\text { executando serviços }\end{array}$ & $\begin{array}{l}\text { O tempo de permanência do empregado } \\
\text { na empresa não será considerado como a } \\
\text { disposição do empregador e sim o } \\
\text { executado }\end{array}$ \\
\hline $\begin{array}{l}\text { Banco de Horas: Deveriam ser negociadas } \\
\text { entre os sindicatos e as empresas, por meio de } \\
\text { convenções ou acordos coletivos }\end{array}$ & $\begin{array}{l}\text { Negociado por acordo individual entre } \\
\text { patrão e empregado }\end{array}$ \\
\hline $\begin{array}{l}\text { Jornada 12x36: admitida somente quando } \\
\text { prevista em lei ou instrumento normativo } \\
\text { decorrente de negociação coletiva }\end{array}$ & $\begin{array}{l}\text { Regulamentada, para } r \text { quaisquer } \\
\text { atividades, mediante acordo individual } \\
\text { escrito. }\end{array}$ \\
\hline $\begin{array}{l}\text { Intervalo intrajornada: Obrigatória a } \\
\text { concessão de intervalo para descanso e refeição } \\
\text { de uma hora }\end{array}$ & Poderá ser de no mínimo 30 minutos, \\
\hline $\begin{array}{l}\text { são de Férias: Gozadas em dois } \\
\text { s desde que não fosse inferior a } 10 \text { dias }\end{array}$ & $\begin{array}{l}\text { Gozadas em até três períodos um com } \\
\text { pelos menos } 14 \text { dias corridos e os demais, } \\
\text { cinco dias corridos }\end{array}$ \\
\hline $\begin{array}{l}\text { Período de amamentação: A lei estabelecia } \\
\text { que para amamentar o próprio filho, até que este } \\
\text { complete } 06 \text { meses de idade, a progenitora tinha } \\
\text { direito a } 2 \text { (dois) descansos especiais, de cada } \\
\text { meia hora cada um }\end{array}$ & $\begin{array}{l}\text { Os períodos deverão ser definidos em } \\
\text { acordo individual entre a progenitora e o } \\
\text { empregador, podendo ser no início da } \\
\text { jornada ou no final, possibilitando redução } \\
\text { da jornada de trabalho. }\end{array}$ \\
\hline $\begin{array}{l}\text { Trabalhador Autônomo: Não é considerado } \\
\text { empregado, desde que atendidos os requisitos } \\
\text { legais. }\end{array}$ & $\begin{array}{l}\text { A contratação do autônomo, cumpridas } \\
\text { por este, todas as formalidades legais, com } \\
\text { ou sem exclusividade, de forma contínua } \\
\text { ou não, afasta a qualidade de empregado } \\
\text { previsto no art. } 3^{\circ} \text { da CLT. }\end{array}$ \\
\hline
\end{tabular}

Fonte: Elaborado pelos autores.

\subsection{JUSTIÇA DO TRABALHO}

O Direito do Trabalho é colocado por Carvalho e Marques (2005) como um conjunto de princípios e normas que disciplinam as relações entre patrões e funcionários. Esse conjunto de normas e princípios é composto pelas leis, decretos-leis, instruções normativas, convenções coletivas de trabalho, acordos coletivos de trabalho, dentre outras, encontradas na Consolidação das Leis do Trabalho (CLT).

Revista Eletrônica do Alto Vale do Itajaí - REAVI, v.09, no 15, p. 013-031, dez. 2020. ISSN: 2316-4190, DOI 10.5965/2316419009152020013 


\section{REAVI}

Segundo os referidos autores, o Direito do Trabalho deve ter como objetivo a proteção do trabalhador, que na relação capital-trabalho mostra-se mais frágil. No contexto da Justiça do Trabalho, encontra-se inserido também o perito-contador, que atua como um auxiliar, mediante o emprego de seus conhecimentos técnicos e científicos.

Segundo Carvalho e Marques (2005):

Constitui prerrogativa do Juiz, no decurso do processo judicial trabalhista - em havendo necessidade - constituir perito contábil para auxiliá-lo no andamento do processo, podendo tal ocorrer tanto na fase de conhecimento - fase cognitiva - que é o momento que antecede a prolação da sentença, quanto no momento da liquidação das obrigações constantes no comando decisório, ou seja, após o trânsito em julgado da sentença.

Com relação à Justiça do Trabalho, a realização da perícia contábil tem sua aplicação no âmbito das demandas trabalhistas, na qual empregador ou empregadores poderão discutir os litígios do setor (JÚNIOR ET AL., 2013).

A Reforma Trabalhista alterou diversos pontos da CLT, e, como foi colocado pelos autores, é a CLT que disciplina as relações no âmbito laboral. Portanto, trouxe para a Justiça do Trabalho a Lei $n^{\circ} 13.467$ de 13 de julho de 2017, referente à reforma trabalhista.

\subsection{MUDANÇAS NA CONSOLIDAÇÃO DAS LEIS DO TRABALHO (CLT)}

Segundo Cezar (2008), a CLT é uma compilação de leis trabalhistas e reúne as normas disciplinares das relações individuais e coletivas de trabalho, além das concernentes a procedimentos administrativos e à Justiça do Trabalho. A CLT foi promulgada no Brasil no dia $1^{\circ}$ de maio de 1943, durante o governo de Getúlio Vargas, pelo Decreto-Lei no 5.452.

Ao longo desses 77 anos, a Consolidação das Leis do Trabalho foi sendo alterada através de inserções de novos artigos e modificações de artigos já existentes. Essas alterações nos dispositivos da CLT tentaram acompanhar as mudanças que ocorreram na sociedade com o passar do tempo, pois em virtude disso, as necessidades e as relações se alteraram. De acordo com Borges (2018, s/p), "Em razão dessa defasagem entre a legislação e essas evoluções, temos a jurisprudência dos tribunais que amoldam, por assim dizer, a interpretação legislativa com o momento de sua aplicação.”.

Recentemente, a Lei $\mathrm{n}^{\mathrm{o}} 13.467$ de 13 de julho de 2017, alterou a CLT em diversos pontos. Essa lei, também chamada de Reforma Trabalhista, já está em vigor desde 11 de novembro de 2017. Segundo Borges (2018), essa foi a maior mudança que já ocorreu na CLT. De acordo com o autor, essas alterações causam uma profunda mudança nas relações de contrato de trabalho e no âmbito do Processo do Trabalho, com consequências imediatas e outras ainda por virem.

Segundo Marinho (2017, s/p), a modernização da Lei trabalhista tem o objetivo de racionalizar as relações de trabalho no Brasil. De acordo com esse autor, a nova lei busca trazer segurança jurídica para quem empreende, mantendo todos os direitos do trabalhador, dinamizando as formas de contratação e ampliando o acesso das pessoas ao mercado de trabalho garantindo as proteções básicas previstas no texto da constituição.

A Reforma Trabalhista é criticada por alguns autores, como por Cassar (2018, s/p), que em seu artigo a respeito desse tema faz a seguinte afirmação para definir a reforma:

Revista Eletrônica do Alto Vale do Itajaí - REAVI, v.09, n 15, p. 013-031, dez. 2020. ISSN: 2316-4190, DOI 10.5965/2316419009152020013 


\section{REAVI}

A Reforma Trabalhista é uma imposição do atual governo, que começou timidamente com um projeto de poucos artigos e se transformou num monstrengo jurídico consubstanciado, hoje, no substitutivo do Projeto de Lei 6787/16.

Como dito pelos autores acima destacados, a nova legislação traz profundas mudanças no âmbito trabalhista. No livro "Trabalhista, O Que Mudou?", de Melek (2017), o autor explica as principais mudanças em sua visão. Algumas dessas mudanças são:

A) Negociado prevalente em relação ao legislado. Antes da Reforma Trabalhista já existia previsão legal sobre o Judiciário observar convenções e acordos coletivos de trabalho, porém o Judiciário poderia anular cláusulas ou convenções inteiras. Agora a nova lei identifica o que pode e não pode ser objeto de negociação coletiva e delimita situações de intervenção do Judiciário de maneira mais objetiva (MELEK, 2017).

B) Autônomo. Antes da reforma a CLT não tratava do autônomo. Agora a nova lei esclarece que não se pode reconhecer vínculo de emprego de quem efetivamente atuou como autônomo, com rendimentos compatíveis, atendendo a formalidades legais e com lei específica que permita (MELEK, 2017).

C) Terceirização. Antes da reforma a terceirização era admitida apenas para atividades "meio". A partir da nova lei a terceirização é admitida para qualquer atividade da empresa, inclusive a "fim" (MELEK, 2017).

D) Teletrabalho. Antes não havia previsão na lei para as pessoas que trabalhavam em casa. A partir da reforma a lei passa a regular o trabalho à distância dando segurança jurídica para às partes (MELEK, 2017).

E) Trabalho Intermitente. Antes da reforma as empresas não poderiam contratar nessa modalidade. A lei cria a nova modalidade de contratação (MELEK, 2017).

F) Trabalho a tempo parcial. Antes a jornada parcial previa duração semanal máxima de 25 horas, não permitia trabalho em horas extras. Agora criou-se a possibilidade da jornada a tempo parcial com horas extras (MELEK, 2017).

G) Fim das horas "in itinere". Antes da reforma, se o empregador fornecesse transporte particular para o empregado, correria sério risco de pagar horas extras pelo tempo itinerário (deslocamento). A partir da nova lei, as horas de deslocamento da casa para o trabalho e vice-versa e, inclusive, do portão da empresa até o efetivo posto de trabalho, não serão considerados tempo à disposição da empresa ou como jornada (MELEK, 2017).

H) Férias. Antes as férias só poderiam ser fracionadas em casos excepcionais e apenas em dois períodos, um dos quais não poderia ser inferior a 10 dias. A partir da reforma o trabalhador pode pedir para que as férias sejam fracionadas em até três períodos, sendo um deles não inferior a 14 dias (MELEK, 2017).

I) Plano de demissão voluntária. Antes da nova lei não havia previsão legal sobre esse tema. Agora a lei trata do alcance da quitação (MELEK, 2017).

J) Petição inicial trabalhista. Antes a petição deveria narrar brevemente os fatos e concluir com pedidos. Agora deve narrar brevemente os fatos e concluir com pedidos certos e determinados (MELEK,2017).

K) Novos critérios para concessão da justiça gratuita. Antes os benefícios da Justiça Gratuita eram concedidos indistintamente a todos os reclamantes na Justiça do Trabalho e as custas processuais eram de $2 \%$ calculadas sobre o valor da causa, se a sentença fosse de improcedência, ou sobre o valor da condenação, se houvesse procedência nos pedidos. A partir da reforma os benefícios da Justiça Gratuita serão

Revista Eletrônica do Alto Vale do Itajaí - REAVI, v.09, n 15, p. 013-031, dez. 2020. ISSN: 2316-4190, DOI 10.5965/2316419009152020013 


\section{REAVI}

concedidos automaticamente a todos os reclamantes que recebem renda individual mensal até $40 \%$ do teto do Regime Geral de Previdência Social, e, acima disso, deverá o reclamante comprovar que não tem condições de arcar com as despesas do processo (MELEK, 2017).

L) Honorários de sucumbência. Antes as Súmulas do TST não permitiam o pagamento de honorários advocatícios na Justiça do Trabalho. A partir da reforma a nova lei prevê o pagamento de honorários advocatícios na Justiça do Trabalho.

M) Dano extrapatrimonial. Antes da reforma não havia critério legal para fixação do valor de reparação moral. Agora a lei cria bandas cada qual com um teto que representa o valor máximo para condenação por reparação moral, assim como também sugere um valor mínimo a ser pago (MELEK, 2017).

Contudo, percebe-se uma melhora e um reconhecimento nos direitos trabalhista inquestionáveis para o trabalhador e empregador, com maior transparência nos conceitos trabalhista. Direitos não reconhecidos anteriormente agora são, como: trabalho intermitente, remuneração paga ano final de cada período de prestação de serviços, dispensa da assistência do sindicato, pagamento das verbas rescisórias, que poderão ser realizadas em dinheiro, depósito bancário ou cheque visado benefícios que antes não existiam. O que acarreta maior segurança para quem emprega, para o trabalhador e facilitando o trabalho também dos agentes intermediários no caso de lide processual.

Em relação aos honorários periciais definitivos, também houve alteração. Atualmente poderão ser cobrados do reclamante, (honorários de sucumbência) mesmo que este seja beneficiário da justiça gratuita, desde que tenho obtido, em juízo, créditos capazes de suportar referida despesa. Em caso negativo, tal encargo continuará a ser repassado às custas da União.

\section{METODOLOGIA}

Quanto aos seus fins, o presente estudo teve como percurso seguido uma pesquisa de caráter exploratório e descritivo baseando-se em Vergara (1997).

O tipo de pesquisa recebe a classificação de exploratória devido ao fato de a Reforma Trabalhista ser muito recente e ainda não ter pesquisas em relação à opinião dos magistrados que atuam no âmbito da Justiça do Trabalho quanto às alterações feitas na CLT. Ou seja, há pouco conhecimento acumulado e sistematizado na área pesquisada.

O caráter descritivo estabelece correlações entre variáveis e expõe características de uma população ou fenômeno. Neste trabalho, busca-se descrever a percepção, expectativas e sugestões acerca da Reforma Trabalhista na ótica dos juízes do Tribunal Regional do Trabalho (TRT) da $10^{a}$ Região, circunscrição de Brasília.

A pesquisa, quanto aos meios, é bibliográfica, documental e de campo. Bibliográfica, pois a fundamentação teórico-metodológica do trabalho realizou-se uma investigação em livros, artigos e meios digitais sobre os seguintes assuntos: responsabilidade do juiz, perícia contábil, laudo pericial, Justiça do Trabalho e consolidação das leis trabalhistas. Classifica-se também, documental, pois utilizou a CLT, o CPC e as NBCs. E por último de campo, pois foram realizadas entrevistas com juízes do TRT 10.

O universo da pesquisa de campo foram os juízes do Tribunal Regional do Trabalho da $10^{\mathrm{a}}$ Região, circunscrição de Brasília. O universo é composto por 22 juízes titulares, dentre eles 15 homens e 7 mulheres, de idades diversas. A amostra foi definida pelo critério de acessibilidade (sem procedimento estatístico, selecionado elementos pela facilidade de acesso

Revista Eletrônica do Alto Vale do Itajaí - REAVI, v.09, n 15, p. 013-031, dez. 2020. ISSN: 2316-4190, DOI 10.5965/2316419009152020013 
aos respondentes), segundo Vergara (2009). A amostra foi composta por 10 magistrados, representando $45,45 \%$ do universo de 22 juízes titulares.

Para conseguir entrevistar os magistrados, foi necessário ir pessoalmente as 22 varas do trabalho do TRT 10, circunscrição de Brasília. Porém, dos 22 juízes titulares das varas, apenas 10 se dispuseram a conceder entrevista.

Para a realização da investigação, utilizou-se um roteiro de entrevista semiestruturada. Segundo Quivy e Campenhoudt (1992), esse tipo de entrevista é o mais utilizado. O investigador possui uma série de perguntas-guias, relativamente abertas, que apesar de ter um roteiro de entrevista, o entrevistado possui alguma liberdade em suas respostas, de modo a ser mais claro quanto ao seu ponto de vista.

Elaborou-se o roteiro de entrevista (Anexo I) para a pesquisa de campo com os magistrados do TRT 10. De forma geral, a estrutura do roteiro de entrevista objetiva captar a opinião dos juízes que atuam na justiça do trabalho em relação às alterações feitas na CLT e como os peritos contábeis os auxiliam para uma justa solução dos litígios que ocorrem no âmbito desse especialista.

Os dados foram analisados a partir da Análise de Conteúdo proposta por Bardin (2011). Tal técnica de pesquisa visa à objetividade, sistematização e inferência. Com ela, o autor representa um conjunto de técnicas de análise das comunicações que tem como objetivo propor procedimentos sistemáticos e objetivos de descrição dos conteúdos das mensagens.

As questões foram no sentido de obter a opinião quanto as principais mudanças, quais os conflitos trabalhistas e sociais poderiam surgir, as mudanças seriam favoráveis a novas contratações trabalhistas no cenário de desemprego de 14 milhões de desempregados, e o papel do perito judicial ainda seria relevante nesse cenário.

\section{ANÁLISE DE DADOS}

A pesquisa constituiu-se de entrevista realizada com dez juízes titulares do TRT-10, circunscrição de Brasília. Objetivou-se captar a opinião dos magistrados em relação à Reforma Trabalhista. Busca-se esclarecer quais foram as principais mudanças na CLT, se houve pontos controvertidos na nova lei, se as novas formas de contratação são benéficas para o trabalhador, se há expectativa de redução no número de processos trabalhistas devido à mudança, se o perito contábil é impactado pelas possíveis alterações na justiça do trabalho e como esse profissional da contabilidade auxiliam os juízes nos conflitos trabalhistas.

Por meio da Análise de Conteúdo de Bardin (2011), as respostas dos entrevistados foram divididas em três subcategorias básicas, no que concerne à categoria referente às alterações mais significativas na CLT, a saber: dos magistrados que citaram a mudança; dos que a citaram como positiva; e dos que a citaram como negativa. Ainda, formularam-se as seguintes categorias: pontos controvertidos na nova lei; novos conflitos; novas formas de contratação; redução do volume de processos desde a Reforma Trabalhista; contribuição do perito contábil para a justiça do trabalho; e o que mudou para os peritos contábeis a partir da nova lei.

\subsection{PRINCIPAIS MUDANÇAS NA CLT}

Em relação às mudanças mais significativas implementadas pela Lei ${ }^{\circ} 13.467$, os magistrados destacam as seguintes:

Revista Eletrônica do Alto Vale do Itajaí - REAVI, v.09, n 15, p. 013-031, dez. 2020. ISSN: 2316-4190, DOI 10.5965/2316419009152020013 


\section{REAVI}

Quadro 01 - Alterações mais significativas na CLT segundo os entrevistados.

\begin{tabular}{|c|c|c|c|}
\hline $\begin{array}{l}\text { Alterações mais significativas na CLT } \\
\text { segundo os entrevistados }\end{array}$ & 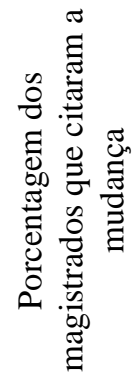 & 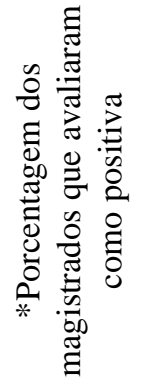 & 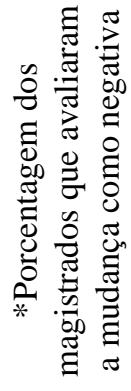 \\
\hline $\begin{array}{c}\text { Previsão de sucumbência recíproca } \\
\text { entre as partes }\end{array}$ & $50 \%$ & $80 \%$ & $20 \%$ \\
\hline $\begin{array}{l}\text { Prevalência do negociado sobre o } \\
\text { legislado }\end{array}$ & $40 \%$ & $25 \%$ & $75 \%$ \\
\hline Fim da contribuição sindical obrigatória & $30 \%$ & $67 \%$ & $33 \%$ \\
\hline Novas formas de contratação & $20 \%$ & - & $100 \%$ \\
\hline Fim das horas in intinere & $10 \%$ & - & $100 \%$ \\
\hline $\begin{array}{c}\text { Espírito filosófico da } \\
\text { Reforma }\end{array}$ & $10 \%$ & $100 \%$ & - \\
\hline $\begin{array}{l}\text { Indicação do valor da causa no início do } \\
\text { pedido }\end{array}$ & $10 \%$ & $100 \%$ & - \\
\hline $\begin{array}{l}\text { Gestantes laborarem em condições } \\
\text { insalubres }\end{array}$ & $10 \%$ & - & $100 \%$ \\
\hline $\begin{array}{c}\text { Tarifação de dano } \\
\text { extrapatrimonial/moral }\end{array}$ & $10 \%$ & - & $100 \%$ \\
\hline
\end{tabular}

Fonte: Elaborado pelos autores

Observa-se, no Quadro 01, que dentre as muitas mudanças que ocorrem na CLT, os magistrados citaram ao todo nove como sendo as mais significativas da Reforma Trabalhista. Essas mudanças foram:

A) previsão de sucumbência recíproca entre as partes - o trabalhador passa a pagar honorários em relação ao pedido que for julgado improcedente, inclusive os periciais, se houver (Art. 790-B. e Art. 791-A. da CLT);

B) prevalência do negociado sobre o legislado, alguns temas podem ser negociados por convenção coletiva de trabalho, acordo coletivo de trabalho e acordo individual (direto com o empregador);

C) fim da contribuição sindical obrigatória, agora a contribuição passa a ser facultativa e condicionada à autorização expressa do trabalhador (Art. 578 e 579 da CLT);

D) novas formas de contratação: trabalho intermitente (Art. 443), trabalho autônomo (Art. 442-B), trabalho por tempo parcial (Art. 58-A), teletrabalho (Art. 75-A) e

Revista Eletrônica do Alto Vale do Itajaí - REAVI, v.09, n 15, p. 013-031, dez. 2020. ISSN: 2316-4190, DOI 10.5965/2316419009152020013 
terceirização das atividades meio e fim (Art. $4^{\circ}$-A);

E) fim das horas in intinere;

F) espírito fillosófico da reforma;

G) indicação do valor no início do pedido (Art. 840);

H) gestantes laborarem em condições insalubres (Art. 394-A);

I) tarifação de dano extrapatrimonial/moral (Art. 223-A).

O Quadro 01 evidencia, também, que, das nove alterações mais relevantes na opinião dos juízes, quatro foram percebidas, pela maioria dos que a citaram, como positivas e 5 foram percebidas como negativas.

\subsection{PONTOS CONTROVERTIDOS NA NOVA LEI}

Todos os juízes entrevistados, ou seja, $100 \%$ da amostra, concordam que a nova lei possui inúmeros pontos controvertidos e até mesmo considerados por eles como inconstitucionais. Como, por exemplo, a previsão de o trabalhador arcar com as custas processuais, mesmo quando for beneficiário da justiça gratuita. Para ser beneficiário da justiça gratuita, é necessário comprovar insuficiência de recursos, logo não é coerente que o reclamante arque com as custas processuais. Um dos juízes afirma que "É incompatível você cobrar custas processuais ou qualquer despesa processual se você defere a gratuidade judiciária. Para mim, isso é inconstitucional, você deferir a justiça gratuita e cobrar custas". Outros exemplos pontuados como sendo controvertidos são: a possibilidade de a gestante ser exposta a condições insalubres de labor e a tarifação de dano extrapatrimonial/moral.

De acordo com o Juiz A, um motivo que deixou a redação da lei com tantos pontos controvertidos é o fato de as questões trabalhistas serem discutidas de uma forma muito setorizada:

Quando se resolvem as coisas setorialmente isso acaba não resolvendo, porque você acaba tentando resolver uma coisa aqui, mas ela faz parte de um conjunto. É você atacar os efeitos e não tratar as causas. A alteração da legislação em si não resolve nada se ela não fizer parte de uma administração do todo.

\subsection{NOVOS CONFLITOS}

Outro ponto de unanimidade entre os magistrados é que, com a nova CLT, surgirão novos conflitos. Inclusive, já surgiram demandas propostas por sindicatos visando a declaração de inconstitucionalidade da reforma na parte que extinguiu a contribuição sindical obrigatória. Os juízes também acreditam que, com as novas formas de contratação (como o trabalho intermitente, a possibilidade de terceirização na atividade fim da empresa e a contratação de autônomos), irão surgir conflitos antes não discutidos nas varas trabalhistas, por se tratar de algo novo.

\subsection{NOVAS FORMAS DE CONTRATAÇÃO}

Quando os juízes foram questionados sobre os impactos das novas formas de contratação que a Lei n 13.467 implementa, as percepções não foram unânimes, conforme se pode observar no Quadro 02, abaixo:

Revista Eletrônica do Alto Vale do Itajaí - REAVI, v.09, n 15, p. 013-031, dez. 2020. ISSN: 2316-4190, DOI 10.5965/2316419009152020013 
Quadro 02 - Novas formas de contratação.

\begin{tabular}{|l|c|}
\hline Novas formas de contratação implementadas pela Reforma Trabalhista & Porcentagem dos magistrados \\
\hline Ganho para o trabalhador & $30 \%$ \\
\hline Precarização das condições de emprego & $70 \%$ \\
\hline
\end{tabular}

Fonte. Elaborado pelos autores

Conforme o Quadro 2, 70\% dos entrevistados acredita que a regularização das novas formas de trabalho irá precarizar ainda mais a relação trabalhista e as condições do trabalhador brasileiro. O Juiz E faz a seguinte declaração:

Se eu puder ser filosófico, a Reforma Trabalhista tem um viés utilitarista. O que ela quer é sacrificar uma pessoa em prol de uma coletividade, isso é o que o utilitarismo de Jeremy Bentham faz. Se tiver uma pessoa no hospital morrendo de câncer, mas ela tiver vários outros órgãos bons para doar, você mata essa pessoa que iria morrer de qualquer jeito para tentar salvar muitas outras vidas. A Reforma Trabalhista é isso, eu vou precarizar as relações de trabalho, mas em compensação eu vou gerar atividade econômica para todo mundo. Para o trabalhador ficou péssimo.

Já 30\% dos juízes entrevistados afirmam que as novas formas de contratação são vantajosas para o trabalhador. Isso se deve ao fato de ela proporcionarem mais liberdade no momento da contratação e ampliarem o leque de empregos. Um dos magistrados afirma o seguinte: “A terceirização é uma forma precária de trabalho? É, mas pelo menos está empregado e recebendo. Considerando a questão da empregabilidade a terceirização é boa, pois traz emprego para muita gente.” Já em relação ao trabalho intermitente o Juiz D alega:

No trabalho intermitente, o empregado pode ter aquele vinculo de emprego com aquela empresa que esteja necessitando daquele serviço só de forma intermitente e pode prestar serviços também para outras empresas ou para outras pessoas. Então, isso beneficiaria o empregado, pois ele poderia manter mais de um vínculo de emprego atendendo a mais de um empregador. $E$ do lado do empregador poderia ter um mesmo empregado prestando serviços a ele de forma intermitente: hoje ele precisa, amanhã não. Então, de acordo com a conveniência do estabelecimento comercial, ele vai usufruir da prestação de serviço desse empregado. E para ele teria vantagem pois ele teria pessoalidade em relação a esse empregado, porque ele não estaria rompendo a cada vez um vínculo e arriscando que a próxima pessoa que ele fosse contratar seja a mesma com aquelas mesmas qualidades, que já estivesse treinada, então ele manteria o vínculo, mas a prestação de serviço não seria continua, mas sim intermitente de acordo com a necessidade da demanda do empregador.

\subsection{REDUÇÃO DO VOLUME DE PROCESSOS DESDE A REFORMA TRABALHISTA}

Quando os magistrados foram indagados sobre a existência de redução no número de processos trabalhistas devido às mudanças na CLT, a resposta foi unânime. Eles alegam que já é um fato a redução drástica no volume de processos nas varas trabalhistas desde que a lei entrou em vigor.

No entendimento dos magistrados o que está ocorrendo é que, agora, o processo trabalhista não é mais gratuito. Até 11 de novembro de 2017, todo processo ajuizado na justiça do trabalho tinha a gratuidade de justiça e, uma mera declaração do reclamante, era admitida como suficiente para garantir essa gratuidade.

Desde a entrada em vigor da Reforma Trabalhista, a mera declaração não basta. Ou há presunção de capacidade de pagamento das custas processuais e honorários de sucumbência

Revista Eletrônica do Alto Vale do Itajaí - REAVI, v.09, n 15, p. 013-031, dez. 2020. ISSN: 2316-4190, DOI 10.5965/2316419009152020013 
pelo valor que o trabalhador recebia de salário ou, então, ele deve comprovar que não tem condição de pagar. Agora o trabalhador não pede na justiça o que sabe que não pode comprovar, pois terá que pagar os honorários da outra parte em caso de improcedência.

O mesmo procedimento se aplicava para os pedidos de perícia. Antes da nova legislação, caso o resultado do laudo fosse negativo para o reclamante, quem pagava os honorários do perito era a União. Agora, cabe ao reclamante arcar com os custos da perícia, caso esta seja negativa para ele.

Por um lado, é interessante a parte autora ter de arcar com as custas processuais, porque faz com que a ação transcorra de forma ética, que não se peça aquilo que não é devido. Com os honorários acontece o mesmo, se o trabalhador pleiteia um pedido e perde, tem que pagar com os honorários advocatícios da parte contrária. A parte irá fazer o pedido apenas se tiver certeza que possui as provas e que o pedido é realmente válido, viável. Isso irá diminuir as chamadas "aventuras jurídicas". O juiz A alega:

\footnotetext{
Muitos pedidos eram feitos de forma irresponsável que geravam improcedências e que não tinham nenhum ônus para o reclamante. Então, a parte autora ficava muito à vontade para usar o processo como se fosse uma loteria: "joga" e caso, por exemplo, se a outra parte não aparece e dá uma revelia ele acaba ganhando algo que efetivamente não tinha direito.
}

O ônus da sucumbência também possui um caráter negativo. Essa alteração pode amedrontar o trabalhador brasileiro, causando-lhe uma espécie de terror, na medida em que mesmo o trabalhador hipossuficiente ou miserável arcará com despesas processuais. O Juiz J afirma:

Evidente que o prejuízo à acessibilidade da jurisdição é certo. Logo, enquanto não houver uma sedimentação de entendimento da Justiça do Trabalho quanto ao resguardo do princípio constitucional da acessibilidade da jurisdição para o trabalhador brasileiro, este continuará amedrontado quanto a buscar a reparação judicial das lesões sofridas.

O Juiz $\mathrm{G}$ faz a seguinte declaração:

Logo depois que a lei entrou em vigor houve uma redução bem grande. Temos uma legislação nova que mudou muita coisa e que restringe o acesso do trabalhador a justiça do trabalho, inclusive ao explicitar a possibilidade de condenar o trabalhador em honorários advocatícios. Então a redução desses processos pode estar associada a essa restrição do acesso a justiça e não uma redução no número de conflitos entre trabalhadores e trabalhadores. Os conflitos tendem a continuar existindo, a lei não traz segurança jurídica.

A redução dos processos nas varas trabalhistas também está relacionada ao fato da mudança ser muito recente. Muitos advogados estão aguardando sair decisões dos juízes e dos tribunais para ver como estes estão procedendo nos processos julgados sobre a nova CLT, e assim terem como elaborar melhor seus pedidos.

\subsection{CONTRIBUIÇÃO DO PERITO CONTÁBIL PARA A JUSTIÇA DO TRABALHO}

Em relação à contribuição do perito judicial para a resolução dos conflitos trabalhistas, os juízes confirmaram o que foi observado durante a pesquisa bibliográfica. O perito judicial visa auxiliar o Juízo no esclarecimento de questões técnicas atinentes às condições do trabalho Revista Eletrônica do Alto Vale do Itajaí - REAVI, v.09, n 15, p. 013-031, dez. 2020. ISSN: 


\section{REAVI}

(insalubridade e periculosidade), acidente e moléstias ocupacionais (nexo causal, redução da capacidade laborativa, sequelas, dano estético, etc) ou aspectos contáveis (cálculos mais complexos). Por certo, sem o auxílio técnico dos peritos judiciais, seria mais difícil o julgamento dos processos trabalhistas que demandam tais conhecimentos técnicos especializados.

No caso específico da justiça do trabalho, há cálculos muito complexos e apenas resolvidos por peritos contábeis, uma vez que o setor de contabilidade do tribunal não detém conhecimento específico para todas as empresas. É indispensável a atuação do perito, sem ele não é possível resolver os processos, afirmam os magistrados.

\subsection{O QUE MUDOU PARA OS PERITOS CONTÁBEIS A PARTIR DA NOVA LEI}

Ao indagar se a Reforma Trabalhista iria impactar os peritos contábeis de alguma maneira, foram obtidos três tipos de respostas, conforme o Quadro 3:

Quadro 03 - O que a Reforma Trabalhista alterou para os peritos contábeis.

\begin{tabular}{|c|c|}
\hline $\begin{array}{c}\text { O que a Reforma Trabalhista alterou para os peritos } \\
\text { contábeis? }\end{array}$ & $\begin{array}{c}\text { Porcentagem dos magistrados entrevistados a citarem } \\
\text { a alteração }\end{array}$ \\
\hline Não terá alteração & $30 \%$ \\
\hline Remuneração dos honorários & $50 \%$ \\
\hline Liquidação dos pedidos desde o início & $30 \%$ \\
\hline
\end{tabular}

Fonte: Elaborado pelos autores

Como é possível observar, $30 \%$ dos magistrados acredita que as mudanças na CLT não irão impactar os peritos contadores, eles continuarão sendo peças fundamentais, porém não sofrerão nenhum impacto com as mudanças.

De acordo com $50 \%$ dos juízes entrevistados, a alteração da lei que faz referência a remuneração dos honorários periciais poderá afetar os peritos contadores. Antes da alteração da CLT, a União pagava para o perito as hipóteses em que o autor da ação fosse sucumbente, caso ele fizesse uso da justiça gratuita e perdesse. Agora será descontado do crédito do reclamante, inclusive caso ele tenha créditos em razão de outros pedidos. De acordo com a lei, é necessário observar o limite traçado pelo Conselho Superior da Justiça do Trabalho. O Conselho Superior fixa os valores máximos que devem ser pagos aos peritos. A respeito dessa alteração o Juiz B faz a seguinte observação:

Se o conselho não se atentar vamos ter problemas futuros, porque o perito não vai vir aqui fazer uma perícia, dependendo da complexidade, pelo valor que foi fixado pelo conselho superior. Então, isso pode acarretar em um prejuízo aqui. Podemos chegar novamente a um período passado onde nós não tínhamos peritos que se habilitassem para trabalhar no processo do trabalho. Isso pode vir a ocorrer novamente.

Outra mudança, citada por $30 \%$ dos entrevistados, é a exigência de que os pedidos sejam liquidados desde o início. A parte vai ter que usar os serviços do perito de uma forma anterior, ou seja, isso poderá aumentar a demanda para os peritos contadores. Escritórios advocatícios contratarão os contadores para atender o que a lei exige: fazer o pedido já com valor certo e determinado. Então, o trabalho que o perito contábil fazia após encerrado o processo (já na fase de execução), ele irá passar a ser demandado já na fase inicial do processo. $\mathrm{O}$ perito terá que assessorar advogados ou escritórios advocatícios nos cálculos para dar

Revista Eletrônica do Alto Vale do Itajaí - REAVI, v.09, nº 15, p. 013-031, dez. 2020. ISSN: 2316-4190, DOI 10.5965/2316419009152020013 


\section{REAVI}

liquidação aos pedidos antes mesmo do início do processo. Isso poderá trazer uma nova demanda de serviços para os profissionais de contabilidade.

\section{CONCLUSÃO}

Conclui-se, a partir da pesquisa realizada, que as mudanças mais significativas na visão dos magistrados são: previsão de sucumbência recíproca entre as partes - o trabalhador passa a pagar honorários em relação ao pedido que for julgado improcedente, prevalência do negociado sobre o legislado, fim da contribuição sindical obrigatória, novas formas de contratação, fim das horas in intinere, espírito filosófico da reforma, indicação do valor no início do pedido, gestantes laborarem em condições insalubres, tarifação de dano extrapatrimonial/moral.

A Reforma Trabalhista possui diversos pontos controvertidos e até mesmo considerados inconstitucionais pelos magistrados. Desde que a nova lei entrou em vigor, em novembro de 2017, o volume de processos nas varas do TRT 10 diminuiu drasticamente, porém isso não é sinônimo de diminuição de conflitos trabalhistas. O que diminuiu, de acordo com os magistrados, foram as "aventuras" jurídicas. Os trabalhadores estão receosos de entrar na justiça sem ter certeza que terão como provar o que está sendo alegado no processo. Isso devido a nova alteração na CLT, em relação ao ônus da sucumbência. A diminuição também está relacionada com o fato de a lei ter entrado em vigor a pouco tempo, os advogados estão esperando ver como será o posicionamento dos juízes e dos tribunais frente a nova lei, para poderem se preparar melhor antes de entrarem com um pedido na justiça trabalhista.

Em relação ao perito contábil no âmbito da justiça trabalhista, conclui-se que seu trabalho é essencial para a elaboração dos cálculos necessários para a justa solução dos litígios laborais. Uma vez que nos processos trabalhistas existem cálculos muito complexos, onde apenas um perito na área é capaz de realiza-lo. A nova CLT traz uma nova possibilidade de trabalho para os profissionais de contabilidade que atuam nessa área, pois agora há a necessidade de os pedidos serem liquidados desde o início. Ou seja, a parte vai fazer uso do trabalho do perito já na fase inicial do processo.

Outra mudança na CLT que poderá afetar o trabalho do perito é em relação aos honorários periciais: a responsabilidade pelo pagamento dos honorários periciais passa a ser da parte sucumbente na pretensão objeto da perícia, ainda que beneficiária da justiça gratuita. $\mathrm{O}$

Conselho Superior da Justiça do Trabalho fixa os valores máximos que devem ser pagos aos peritos. Caso o conselho não se atentar quanto ao valor fixado, isso poderá levar a uma carência de peritos contábeis que queiram atuar nos processos trabalhistas. $\mathrm{O}$ perito não irá fazer o cálculo por um valor que ele considere ser incompatível com a complexibilidade do trabalho. Isso irá gerar um prejuízo para a justiça do trabalho, que necessita muito de bons profissionais da área de contabilidade atuando na perícia para auxiliar os magistrados.

\section{REFERÊNCIAS}

BARDIN, Laurence. Análise de conteúdo. São Paulo: Edições 70, 2011.

BRASIL. Consolidação das leis do trabalho. Decreto-lei $n^{\circ} 5.452$, de $1^{\circ}$ de maio de 1943.

BRASIL. CPC. Código de Processo Civil. Lei n ${ }^{\circ}$ 13.105, de 16 de março de 2015. Disponível em: http://www.planalto.gov.br/ccivil_03/_ato2015-2018/2015/lei/113105.htm. Acesso em 19 de maio de 2018.

Revista Eletrônica do Alto Vale do Itajaí - REAVI, v.09, nº 15, p. 013-031, dez. 2020. ISSN: 2316-4190, DOI 10.5965/2316419009152020013 
BRASIL. Lei $\mathbf{n}^{\mathbf{0}}$ 13.467, de 13 de julho de 2017. Altera a Consolidação das Leis do Trabalho, Brasília, DF, jul. 2017.. CFC. NBC T 13.4.2. Normas Brasileiras de Contabilidade - NBC T 13.4.2 da perícia contábil, de 27 de fevereiro de 2015.

BRASIL. CFC. NBC TP 01. Normas Brasileiras de Contabilidade - NBC TP 01, de 27 de fevereiro de 2015.

BRASIL. CFC. NBC. Normas Brasileiras de Contabilidade - NBC PP 01, de 27 de fevereiro de 2015.

CALDEIRA, Sidenei. A influência do laudo pericial contábil na decisão dos juízes em processos nas varas cíveis. 2000. 113f. Dissertação de Mestrado - Universidade Federal de Santa Catarina, Florianóplois, 2000.

CARVALHO, Edjan Baldo e MARQUES, Claudio. Perícia contábil nas relações de trabalho em processos judiciais. Enfoque reflexões contábeis, v.24, n.2, p. 36-52, JulhoDezembro/2005.

CEZAR, Frederico Gonçalves. O processo de elaboração da CLT: histórico da consolidaçao das leis trabalhistas brasileiras em 1943. Revista Processus de Estudos de Gestão, Jurídicos e Financeiros - Ano 3 - Edição No 07, p.13-20, ISSN 2178, 2008.

CNC. A Reforma Trabalhista - A nova Consolidação das Leis do Trabalho. Confederação Nacional do Comércio de Bens, Serviços e Turismo, CNC, 2017.

DIAS, Glauco Braga; CAVALCANTE, Luiz Ricardo Mattos Teixeira. Custos, insegurança jurídica e terceirização: percepção das empresas. Direito e Desenvolvimento, v. 10, n. 2, p. 222-240, 2019.

FIGUEIRAS, V.A., LIMA, U.M., \& SOUZA, I.F.D.(2019). Os impactos jurídicos, econômicos e sociais das reformas trabalhistas. Caderno CRH, 32(86),231-252

FIGUEIREDO, Sandoval Nunes. A perícia contábil e a competência profissional. Revista Brasileira de Contabilidade, n. 142, p. 40-47, jul./ago. 2003.

JÚNIOR, Idalberto José das Neves et al. Pericia Contábil Judicial: A Relevância e a Qualidade do Laudo Pericial Contábil na Visão dos Magistrados do Estado do Rio de Janeiro. Pensar Contábil, Rio de Janeiro, v.16, n.59, p.49-57, jan./abril 2014.

JÚNIOR, Idalberto Jose das Neves; MOREIRA, Simone Alves; RIBEIRO, Elisangela Batista; SILVA, Moacenira Cardoso. Perícia Contábil: estudo da percepção de juízes de Primeira Instância na Justiça do Trabalho sobre a qualidade e a relevância do trabalho do perito. Revista Brasileira de Gestão de Negócios, São Paulo, v.15, nº47, p.300-320, abr/jun. 2013.

Revista Eletrônica do Alto Vale do Itajaí - REAVI, v.09, n 15, p. 013-031, dez. 2020. ISSN: 2316-4190, DOI 10.5965/2316419009152020013 


\section{REAVI}

MATHIAS, Linda Rose Gimenez Mola; JUNIOR, Valdir Serafim. IMPACTOS DA REFORMA TRABALHISTA NA PERÍCIA CONTÁBIL SOB A PERSPECTIVA DOS PERITOS CONTÁBEIS DO TRT 9 $9^{\mathrm{a}}$ REGIÃO DO ESTADO DO PARANÁ. RAGC, v. 8, n. 37, 2020.

MELEK. Trabalhista! O que mudou? 3. Ed. Curitiba: Estudo Imediato Editora, 2017

QUIVY, Raymond; CAMPENHOUDT, Luc Van. Manual de Investigação em Ciências Sociais. $1^{a}$ ed., Lisboa, Gradiva, 1992.

SANTOS, Chayenne Pereira dos. Reforma trabalhista: a inconstitucionalidade do quantum indenizatório extrapatrimonial por critério da percepção salarial do trabalhador. 2017.

VERGARA, Sylvia Constant. Projeto e Relatórios de Pesquisa em Administração. 11. Ed. São Paulo: Atlas, 2009 (1997).

Revista Eletrônica do Alto Vale do Itajaí - REAVI, v.09, nº 15, p. 013-031, dez. 2020. ISSN: 